\title{
Factors Predicting Treatment Outcome in Hospitalized Patients with Acute Exacerbation of COPD (AECOPD)
}

\author{
Abhay Uppe, Padmaraj Ankale, Arti Sharma, Ria Shah, Girija Nair \\ Department of Pulmonary Medicine, D. Y. Patil Medical College, Nerul, Navi Mumbai, India \\ Email address: \\ abhay.uppe@dypatil.edu (A. Uppe) \\ ${ }^{*}$ Corresponding author

\section{To cite this article:} \\ Abhay Uppe, Padmaraj Ankale, Arti Sharma, Ria Shah, Girija Nair. Factors Predicting Treatment Outcome in Hospitalized Patients with \\ Acute Exacerbation of COPD (AECOPD). American Journal of Internal Medicine. Vol. 6, No. 4, 2018, pp. 82-85. \\ doi: 10.11648/j.ajim.20180604.16
}

Received: June 28, 2018; Accepted: July 17, 2018; Published: August 14, 2018

\begin{abstract}
Objective: The aim of our study was to study the COPD phenotypes, comorbidities and factors predicting treatment outcomes in patients with acute exacerbations of COPD admitted in hospital. Methodology: A retrospective study of fifty patients with acute exacerbation of COPD admitted in a tertiary care hospital during July 2015 to August 2016 was done. Results: It was observed that the mean duration of hospital stay was $8 \pm 7$ days with $44 \%$ of the patient discharged in less than 7 days (short stay) and $56 \%$ of patients in more than 7 days (long stay). The factors favouring longer stay in hospital include history of current smoking, hypoxia and $\mathrm{CO}_{2}$ retention while patients on active COPD treatment and cessation of smoking leads to shorter hospital stay. Conclusion: For patients with acute exacerbations of COPD requiring hospitalization, history of current smoking with hypoxia and $\mathrm{CO}_{2}$ retention are associated with longer stay in hospital while patients on active COPD treatment and cessation of smoking leads to shorter hospital stay.
\end{abstract}

Keywords: COPD, Hospital Mortality, Intensive Care Unit (ICU), Non-Invasive Ventilation (NIV)

\section{Introduction}

Chronic obstructive pulmonary disease (COPD) is a lung ailment that is characterized by a persistent blockage of airflow from the lungs. It is an under-diagnosed, lifethreatening lung disease that interferes with normal breathing and is not fully reversible. The more familiar terms of chronic bronchitis and emphysema are no longer used; they are now included within the COPD diagnosis. It is a major cause of morbidity and mortality worldwide and accounts for a significant proportion of patient visits to the emergency department and hospitalizations. More than 3 million people died of COPD in 2012, which is equal to $6 \%$ of all deaths globally that year. More than $90 \%$ of COPD deaths occur in low- and middle-income countries. The primary cause of COPD is tobacco smoke (through tobacco use or secondhand smoke). The disease now affects men and women almost equally, due in part to increased tobacco use among women in high-income countries. Most patients with acute exacerbations of COPD do well after a course of inhaled bronchodilators, systemic corticosteroids, and/or antibiotics. A small number, however, develop acute respiratory failure and require intensive care management with mechanical ventilation (MV). Acute exacerbation of COPD requiring care in the intensive care unit (ICU) constitutes a specific interest group because of the significant healthcare burden they pose. There have been several papers published in America and Europe which have studied this specific group of patients [1-5]. Similar studies in Asia are lacking [6-7]. Thus, the aims of our study were to study the COPD phenotypes, Comorbidities and factors predicting treatment outcomes in patients with acute exacerbations of COPD admitted in hospital.

\section{Materials and Methods}

The present retrospective study was carried out over a oneyear period from July 2015 to August 2016 in the 
Department of Pulmonary Medicine, Dr. D. Y. Patil Hospital, Nerul, Navi Mumbai, Maharashtra. Ethical approval was taken from the University ethical committee before starting the study. Oral and written consent was taken from all participants.

The records for 50 consecutive admissions with acute exacerbation of COPD were reviewed. The inclusion criteria included a definite history of smoking and a diagnosis of COPD based on spirometric evidence of obstruction according to European Respiratory Society criteria [8]. Exclusion criteria included a clinical diagnosis only for COPD, without any spirometric evidence, and admission to the ICU for any cause other than acute exacerbation of COPD, such as pneumonia. The decision to admit a patient for COPD exacerbation is made by the attending physician in collaboration with the intensivist, when indications for admission are present. Initiation of non-invasive mechanical ventilation (NIV) or $\mathrm{MV}$ is determined by the attending intensivist based upon the following: (i) acute hypoxaemic respiratory failure: arterial oxygen tension $(\mathrm{PaO} 2)<60 \mathrm{mmHg}$, despite oxygen therapy; and (ii) acute hypercapnic respiratory failure: arterial carbon dioxide tension $(\mathrm{PaCO} 2)>50 \mathrm{mmHg}$, accompanied by acidosis $(\mathrm{pH}<7.30)$. Exclusion criteria for NIV in our ICU include the following: (i) post-cardiac arrest; (ii) uncooperative or mentally obtunded patient; (iii) haemodynamic instability or unstable cardiac arrhythmia; (iv) inability to clear airway secretions; (v) poor respiratory drive; (vi) inability to achieve mask fit; (vii) acute upper gastrointestinal bleeding or severe epistaxis; and (viii) history of allergy or hypersensitivity to mask material.

The treatment of acute exacerbation of COPD in our ICU typically includes bronchodilator therapy consisting of nebulized salbutamol and ipratropium bromide given at regular intervals usually every 4-6 h, intravenous corticosteroids (intravenous hydrocortisone, $100 \mathrm{mg}$ every 6 $\mathrm{h}$ ), and systemic antibiotics, where indicated. The decision to discontinue NIV and MV is made by the attending intensivist when the underlying disease process has subsided. Discontinuation of NIV is considered when: (i) respiratory rate has decreased to $<20$ breaths/min; (ii) bronchospasm has resolved on lung auscultation; (iii) arterial blood gas $\mathrm{pH}$ has improved; and (iv) $\mathrm{FiO} 2<0.4$ with $\mathrm{SaO} 2>92 \%$ or $\mathrm{PaO} 2>65 \mathrm{mmHg}$. Discontinuation of $\mathrm{MV}$ is considered when: (i) bronchospasm has resolved on lung auscultation; (ii) patient is awake and cooperative without any sedation; (iii) arterial blood gas $\mathrm{pH}$ has improved; and (iv) patient has passed a spontaneous breathing trial consisting of: (a) positive end-expiratory pressure of $5 \mathrm{~cm}$ of $\mathrm{H} 2 \mathrm{O}$; (b) pressure support of $10 \mathrm{~cm}$ of $\mathrm{H} 2 \mathrm{O}$ or less; (c) $\mathrm{FiO} 2<0.4$ with $\mathrm{SaO} 2>92 \%$ or $\mathrm{PaO} 2>65$ $\mathrm{mmHg}$; and (d) rapid shallow breathing index $<105$ breaths $/ \mathrm{min} / \mathrm{mL}$. The decision to discharge patients from the ICU rests with the attending intensivist. This is considered when there is stabilization of the patient's physiological status, discontinuation of $\mathrm{MV}$, and cessation of the need for an ICU level of monitoring and care.

\section{Results}

Between July 2015 and August 2016, there were a total of 78 admissions with a diagnosis of COPD. However, 28 admissions were excluded because they were either admitted for medical ailments other than COPD exacerbation or there was no spirometric evidence of obstruction. As a result, there were 50 admissions that fulfilled our inclusion criteria. The demographic and clinical characteristics of the patients are summarised in Table 1.

Table 1. Demographic and clinical characteristics of Hospital admissions with acute exacerbation of $C O P D$.

\begin{tabular}{lll}
\hline Characteristic & n (\%) & SD \\
\hline Gender & $32(64 \%)$ & \\
Male & $18(36 \%)$ & \\
Female & 38.12 & 13.81 \\
Age (years) & 20.94 & 8.59 \\
Age of onset (years) & 17.18 & 8.96 \\
Duration of illness (years) & & \\
Comorbidities & $12(24 \%)$ & \\
Diabetes mellitus & $11(22 \%)$ & \\
hypertension & $1(2 \%)$ & \\
Thyroid disorders & $4(8 \%)$ & \\
OSA & $2(4 \%)$ & \\
IHD & & \\
Method of ventilation & 29 & \\
Oxygen therapy & 11 & \\
NIV & 10 & \\
MV alone & 1 & \\
Duration of NIV (days) & 1 & \\
Duration of MV (days) & & \\
FEV1 & 10.3 \\
pre-admission & 0.8 & \\
post-admission & 0.9 & 0.3 \\
Smoking history & & \\
Stopped Smoking & $23(46 \%)$ & \\
Current smokers & $10(20 \%)$ & \\
Amount smoked & & \\
Stopped Smoking (pack-years) & & \\
Current smokers (pack-years) & & \\
Length of stay & & \\
hospital (days) & & \\
\hline & & \\
\hline
\end{tabular}

\section{Outcome Analysis}

The results are summarised in Table 2 . There was only one (2\%) hospital death attributed to COPD. It was due to worsening respiratory failure and subsequent cardiopulmonary arrest.

It was observed that the mean duration of hospital stay was $8 \pm 7$ days with $44 \%$ of the patient discharged in less than 7 days (short stay) and $56 \%$ of patients in more than 7 days (long stay).

In short stay group $45.5 \%(\mathrm{n}=10)$ had diabetes mellitus, $31.8 \%(n=7)$ had hypertension, and $9.09 \%(n=2)$ with obstructive sleep apnoea and in long stay group 7.4\% $(\mathrm{n}=2)$ had diabetes, OSA and IHD each and 14.8\% (n=4) had hypertension. Among smokers who stopped smoking 56.5\% $(n=13)$ required short stay and 39.1\% $(n=9)$ required long stay in hospital and $4.3 \%(\mathrm{n}=1)$ died and in current smokers $40 \%(n=4)$ required short stay and $60 \%(n=6)$ required long 
stay. $58.5 \%$ patients who are currently taking active treatment required short stay. It was also observed that $70 \%$ of patients with hypoxia $(n=35)$ and $82 \%$ of patients with $\mathrm{CO} 2$ retention required long stay in hospitals.

Table 2. Analysis of hospital stay.

\begin{tabular}{llll}
\hline Characteristic & short stay $(\leq 7$ days) & long stay $(\geq \mathbf{8}$ days) & Death \\
\hline $\mathrm{N}(\%)$ & $22(44 \%)$ & $27(54 \%)$ & $1(2 \%)$ \\
Male & $14(43.8 \%)$ & $17(53.1 \%)$ & $1(3.1 \%)$ \\
Female & $10(55.6 \%)$ & $8(44.4 \%)$ & \\
Comorbidities & & & \\
Diabetes mellitus & $10(83.3 \%)$ & $2(16.6 \%)$ & \\
hypertension & $7(63.6 \%)$ & $4(36.4 \%)$ & \\
Thyroid disorders & $2(50 \%)$ & $2(50 \%)$ & $1(10 \%)$ \\
OSA & 0 & $2(100 \%)$ & $1(4.3 \%)$ \\
IHD & & & \\
Method of ventilation & $18(62.1 \%)$ & $11(37.9 \%)$ & \\
Oxygen therapy & $5(45.5 \%)$ & $6(54.5 \%)$ & \\
NIV & $4(40 \%)$ & $5(50 \%)$ & \\
MV alone & & $9(39.1 \%)$ & \\
Smoking history & $13(56.6 \%)$ & $6(60 \%)$ & \\
Stopped smoking & $4(40 \%)$ & $4(40 \%)$ & \\
Current smokers & $6(60 \%)$ & $35(41.5 \%)$ & \\
Previous hospitalization & $24(58.5 \%)$ & $41(82 \%)$ & \\
On treatment & $15(30 \%)$ & & \\
Hypoxia & $9(18 \%)$ & & \\
CO2 retention & & & \\
\hline
\end{tabular}

\section{Discussion}

In this study male: female ratio was $1.78: 1$ which is consistent with the data from other countries [9]. Overall there was no ICU mortality. All the patients admitted in ICU were weaned off MV and discharged. NIV is commonly used in patients with COPD as an alternative to MV both in ICU and wards. The median duration of NIPPV of 1 day was slightly shorter when compared to other studies [10-12]. Traditionally, there have been concerns with MV patients with COPD, especially with regards to difficult weaning, prolonged ventilation, complications of ventilation, and increased hospital costs. Several studies have recently demonstrated that prolonged MV is not a significant clinical problem for the majority of intubated COPD patients, with the duration of MV being 3-4 days [13-14]. In our study, the median duration of MV was similarly short (1 day). The use of MV was also not associated with poor hospital outcome in our study. In our study cohort we found that smoking cessation and active treatment has favorable outcomes with shorter hospital stay. Our study has several limitations. Being a retrospective study, it was limited by potential bias in the investigator assessment of case records and by inaccuracies in data documentation and discharge diagnostic coding. The total number of admissions was small; hence, our study may not have been adequately powered to detect the effect of certain variables with respect to ICU and hospital mortality. Potential selection bias for patients who gained admission to the ICU also needs to be considered in the interpretation of the results.

\section{Conclusion}

For patients with acute exacerbations of COPD requiring hospitalization, history of current smoking with hypoxia and $\mathrm{CO} 2$ retention are associated with longer stay in hospital while patients on active COPD treatment and cessation of smoking leads to shorter hospital stay.

The authors declare that they have no competing interests.

\section{Funding}

The author(s) received no financial support for the research, authorship, and/or publication of this article.

\section{References}

[1] Batzlaff CM, Karpman C, Afessa B, Benzo RP. Predicting 1year mortality rate for patients admitted with an acute exacerbation of chronic obstructive pulmonary disease to an intensive care unit: an opportunity for palliative care. Mayo Clin Proc. 2014 May; 89 (5):638-43. doi: 10.1016/j.mayocp.2013.12.004. Epub 2014 Mar 19.

[2] Ocal S, Ortac Ersoy E, Ozturk O, Hayran M, Topeli A, Coplu L. Long-term outcome of chronic obstructive pulmonary disease patients with acute respiratory failure following intensive care unit discharge in Turkey. Clin Respir J. 2017 Nov; 11 (6):975-982. doi: 10.1111/crj.12450. Epub 2016 Feb 15.

[3] Alaithan AM, Memon JI, Rehmani RS, Qureshi AA, Salam A Chronic obstructive pulmonary disease: hospital and intensive care unit outcomes in the Kingdom of Saudi Arabia. Int J Chron Obstruct Pulmon Dis. 2012; 7:819-23. doi: 10.2147/COPD.S37611. Epub 2012 Dec 18.

[4] Gadre SK, Duggal A, Mireles-Cabodevila E, Krishnan S, Wang XF, Zell K, Guzman J. Acute respiratory failure requiring mechanical ventilation in severe chronic obstructive pulmonary disease (COPD). Medicine (Baltimore). 2018 Apr; 97 (17):e0487. doi: 10.1097/MD.0000000000010487. 
[5] Alvisi V, Romanello A, Badet M, Gaillard S, Philit F, Guérin C. Time course of expiratory flow limitation in COPD patients during acute respiratory failure requiring mechanical ventilation. Chest. 2003 May; 123 (5):1625-32.

[6] Dikensoy O, Ikidag B, Filiz A, Bayram N. Comparison of non-invasive ventilation and standard medical therapy in acute hypercapnic respiratory failure: a randomised controlled study at a tertiary health centre in SE Turkey. Int. J. Clin. Pract. 2002; 56: 85-8.

[7] Agarwal R, Gupta R, Aggarwal AN, Gupta D. Noninvasive positive pressure ventilation in acute respiratory failure due to COPD vs other causes: effectiveness and predictors of failure in a respiratory ICU in North India. Int $\mathrm{J}$ Chron Obstruct Pulmon Dis. 2008; 3 (4):737-43.

[8] Abdullah N, Borhanuddin B, Shah SA, Hassan T, Jamal R. Global Lung Initiative 2012 spirometry reference values in a large Asian cohort of Malay, Chinese and Indian ancestry. Respirology. 2018 May 22. doi: 10.1111/resp.13330. [Epub ahead of print].

[9] National Heart, Lung, and Blood Institute. Unpublished Tabulations from the World Health Organization Mortality Database (Accessed March 2011). Available at: http://www.who.int/whosis/ mort/download/en/index.html.

[10] García-Sanz MT, González-Barcala FJ, Cánive-Gómez JC, García-Couceiro N, Alonso-Acuña S, Carreira JM. Prolonged stay predictors in patients admitted with chronic obstructive pulmonary disease acute exacerbation. Lung India. 2018 JulAug; 35 (4):316-320. doi:

10.4103/lungindia.lungindia 46917.

[11] Lemyre B, Davis PG, De Paoli AG, Kirpalani H. Nasal intermittent positive pressure ventilation (NIPPV) versus nasal continuous positive airway pressure (NCPAP) for preterm neonates after extubation. Cochrane Database Syst Rev. 2017 Feb 1; 2:CD003212. doi: 10.1002/14651858.CD003212.pub3. Review.

[12] Osadnik CR, Tee VS, Carson-Chahhoud KV, Picot J, Wedzicha JA, Smith BJ. Non-invasive ventilation for the management of acute hypercapnic respiratory failure due to exacerbation of chronic obstructive pulmonary disease. Cochrane Database Syst Rev. 2017 Jul 13; 7:CD004104. doi: 10.1002/14651858. CD004104.

[13] Ocal S, Ortac Ersoy E, Ozturk O, Hayran M, Topeli A, Coplu L. Long-term outcome of chronic obstructive pulmonary disease patients with acute respiratory failure following intensive care unit discharge in Turkey. Clin Respir J. 2017 Nov; 11 (6):975-982. doi: 10.1111/crj.12450. Epub 2016 Feb 15.

[14] Messer B, Griffiths J, Baudouin SV. The prognostic variables predictive of mortality in patients with an exacerbation of COPD admitted to the ICU: an integrative review. QJM. 2012 Feb; 105 (2):115-26. doi: 10.1093/qjmed/hcr210. Epub 2011 Nov 8. Review. 